\title{
Assessment and Attainment of Program Educational Objectives for Post Graduate Courses
}

\author{
Akash Rajak \\ KIET Group of Institutions, Ghaziabad, India \\ Email: akashrajak@gmail.com \\ Ajay Kumar Shrivastava \\ KIET Group of Institutions, Ghaziabad, India \\ Email: ajay@kiet.edu \\ Shashank Bhardwaj \\ KIET Group of Institutions, Ghaziabad, India \\ Email: shashank.bhardwaj@kiet.edu \\ Arun Kumar Tripathi \\ KIET Group of Institutions, Ghaziabad, India \\ Email: arun.tripathi@kiet.edu
}

Received: 11 October 2018; Accepted: 16 December 2018; Published: 08 February 2019

\begin{abstract}
As per the guidelines issued by NBA (National Board of Accreditation) of All India Council of Technical Education (AICTE) Outcome Based Education is implemented in engineering colleges of India. The outcome based evaluation model measures the performance of UG and PG programs. The performance is based on calculating attainments of Program Educational Objectives (PEOs) and Program Outcomes (PO).In this paper we will discuss the process for the attainments of POs and PEOs for Post Graduate program approved by AICTE, India. The attainments are calculated by applying direct and indirect tools. The attainments summaries are generated Batch wise and a comparison of different Batches were made. The attained PEOs and POs would help in accomplishing Vision and Mission of the department.
\end{abstract}

Index Terms-Course Outcome, Outcome Based Education, PO, PEO, Data Analytics.

\section{INTRODUCTION}

The Outcome Based Education (OBE) is adopted by AICTE from Washington Accord on 13 June 2014[1]. All the technical institutions of India are following OBE as per the guidelines issued by AICTE. OBE is outcome based learning in which the engineering graduates are trained so as to have better knowledge, skill sets and attitudes. In OBE certain targets are set and teaching learning activities are properly planned and organized to achieve the targets. In case if there is any deviation from targets then gap analysis is performed. For continuous improvement targets are revised from time to time based on vision and mission of the department or institute. The
OBE process starts from defining vision and mission of the department in accordance to vision and mission of institute. The Program Educational Objectives (PEOs) and Program Outcomes (POs) are formulated as per vision and mission of institute and NBA graduate attributes. The next step is to design Course Outcomes (COs) for different courses and surveys like alumni, employer etc. A mapping of COs with POs is established having strong, moderate and weak correlation. In the research paper we will discuss the attainment process of PEOs and POs.

\section{BACKGROUND}

The AICTE approved colleges in India follows OBE model which is adopted from Washington Accord [1,2]. The idea behind the implementation of OBE model is that graduate should posses a sound knowledge in the field but also can have global mobility and acceptance [3]. Malaysian engineering education also adopted outcome based education approach [4]. Bassi et al. [5] discussed the analysis of the students in different academic and non-academic activities by using OBE model. They examined the students whose targets were not achieved. Terang et al. [6] discussed the methodology to identify weak students for the subject Electromechanical Energy Conversion II. They took some corrective actions if the targets were not archived by the students [6]. The authors discussed about the methodology for the assessment of $\mathrm{CO}$ of an each and every student against pre-defined target [7]. Roy et al. [8] discussed an innovative approach to evaluate the CO's of the course Power Quality and its relationship with POs of Electrical Engineering. They further mapped the Cos with POs of the department. 
Rajak et al. [9] discussed how to automate outcome based education for the attainment of PEOs and POs. Wong et al. [10] implemented OBE from the program design perspective and discusses importance of OBE in teaching. Tshai et al. [11] formulated the OBE process in integration with stakeholders and identified set of strategies for continuous quality improvement (CQI). The authors discussed an OBE framework and implemented it in Object-Oriented Software Development course [12]. The motivation of this research is to automate the outcome based process and to find the attainments of any PG program.

\section{ATtAINMENT PROCESS}

The attainment process involves designing and calculating attainments of Program Educational Objectives, Program Outcomes and Course Outcomes.

It consists of following steps:

- Defining department Vision and Mission.

- Formulation of PEO and PO in alignment to Vision and Mission.

- Correlation between PEO and PO.

- Design of Course Outcome for different assessment tools like subjects, projects and various surveys.

- Establish mapping of CO with PO for different courses having strong (3), moderate (2) and weak (1) correlation.

- Calculate CO attainment from Figure 1 and 2.

- Finally predict PEO and PO attainments.

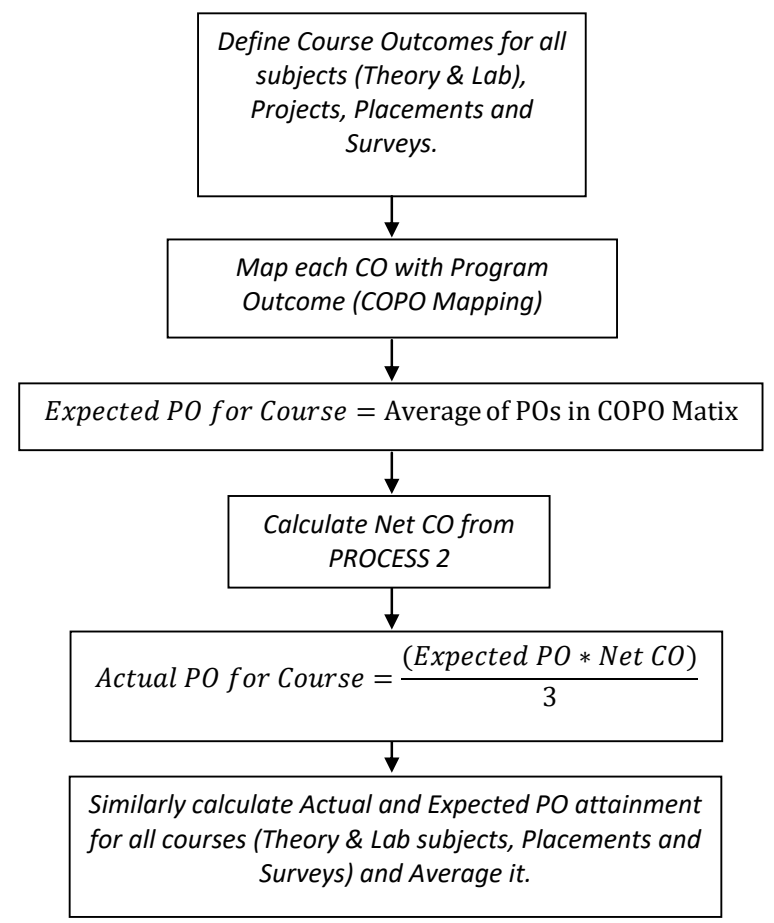

Fig.1. Process 1-PO Attainment

The Figure 1 gives the various steps involved in the attainment process. The process starts from defining
Course Outcomes for different courses, then establishing correlation between $\mathrm{CO}-\mathrm{PO}$ and finally calculating the attained PO and PEOs.

The Figure 2 gives a detail on Net $\mathrm{CO}$ calculation. The Direct and Indirect tools were involved in calculating PEO and PO attainments. The Direct tools include various theory and practical subjects, projects and placements. The indirect tools consist of various surveys. In case of theory subjects the contribution of external is $70 \%$ and internal is $30 \%$ in calculating Net CO attainment. For placements and surveys a target is fixed and on that basis Net $\mathrm{CO}$ is calculated. For e.g. if the placement is more than or equal to $75 \%$ then the attainment is 3 .

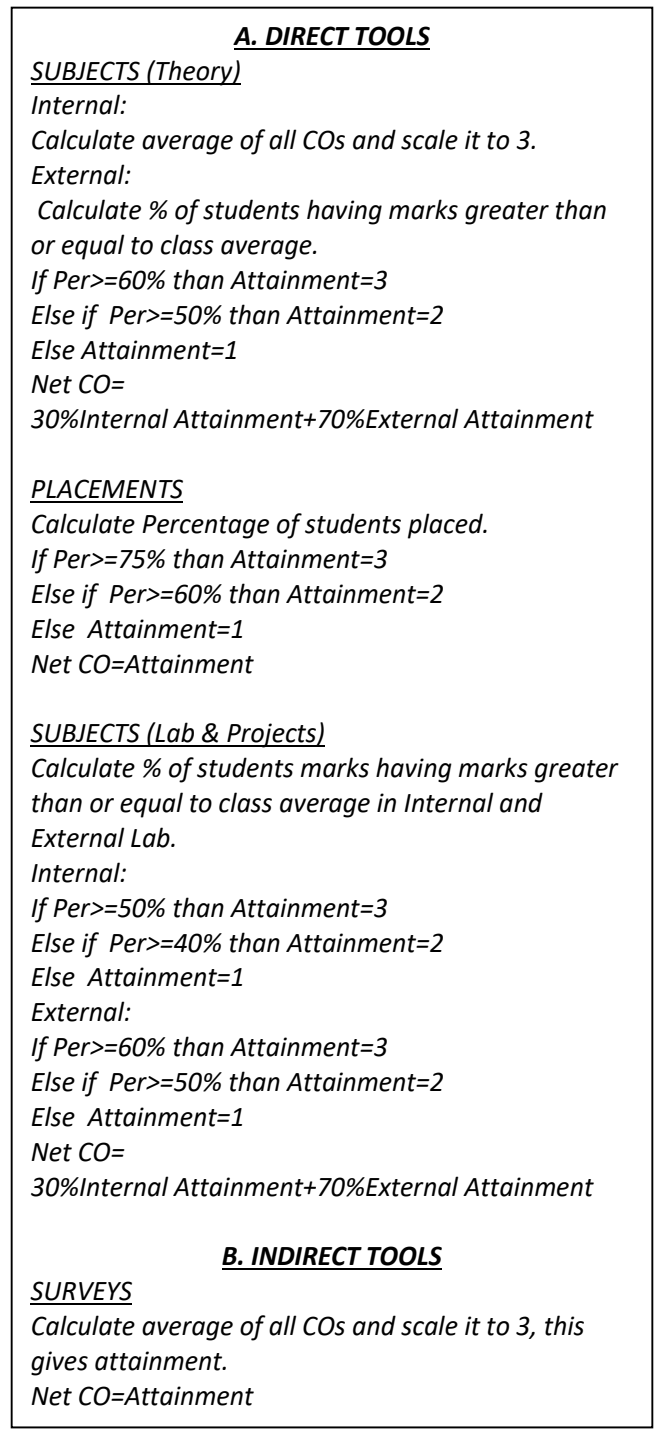

Fig.2. Process 2-Net CO Calculation

The Figure 3 gives final PO and PEO attainment. In final evaluation of PEO and PO attainments $50 \%$ weightage for direct and $50 \%$ weightage for indirect tools are given. While calculating direct attainment some weightage is to be given for subjects, projects and placements. Similarly while calculating indirect attainment some weightage is to be given for various surveys depending on its impact on attainments. 


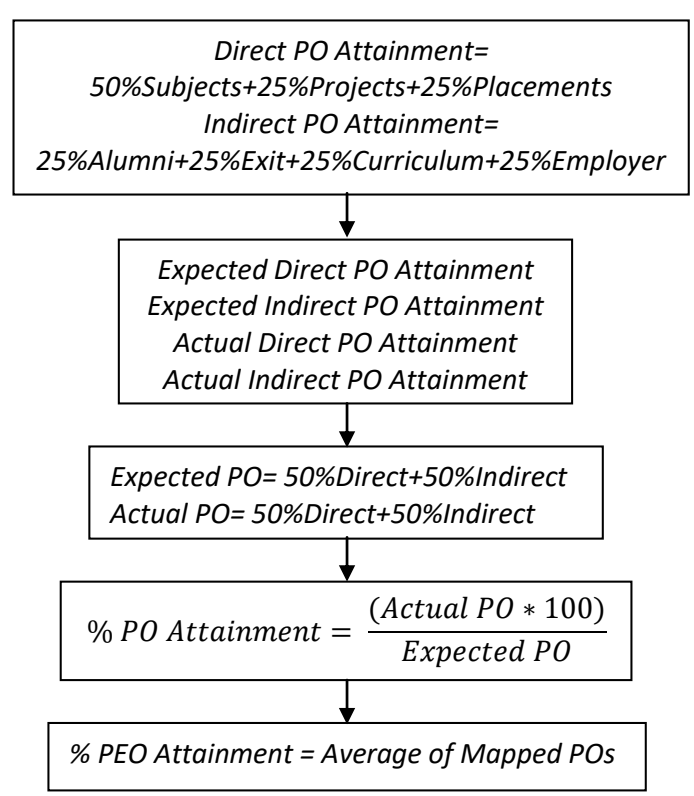

Fig.3. Process 3-PO and PEO Attainments

The percentage of PO attainment is measure by Actual PO and Expected PO. As stated earlier a correlation is to be established between PEOs and POs and based on these mappings the percentage PEO attained is calculated. For e.g. PEO5 is mapped with PO3, PO10, PO11 and PO12. The average of PO3, PO10, PO11 and PO12 gives attained PEO5. A comparison of PEOs and POs for different batches could help in assessing the PG program. In case of any weak attainment gap analysis can be performed. This OBE model could also help in designing of PG curriculum.

\section{COURSE OUTCOME ESTIMATION}

\section{A. Course Outcome}

The Course Outcome for any course can be formulated in form of various sentences giving the expected outcome of a particular course or what the students would get at the end of the course. The Course Outcomes are formulated by subject expert by involving various stake holders like Alumni, Industry etc. The Course Outcome of PG subject Computer Graphics is as follows.

The students would able:

- To understand the concepts of computer graphics and implementation of image creation and filling algorithms.

- To understand the concept of viewing and implement clipping algorithms \& transformations.

- To understand the concept of projection and theory related to visible surface detection.

- To implement Bezier curves and study concepts related to illumination models.

- To understand fundamentals of animation and its techniques.

\section{B. Mapping and CO Estimation}

The department of MCA has formulated 12 POs based on twelve NBA graduate attributes. A correlation of various courses is established with Program Outcomes based on strong (3), moderate (2) and weak (1) correlation. It is shown in Table 1. In CO-PO Mapping Table the average of different columns gives Expected PO. The Actual PO is calculated through Net CO. In Net CO calculation $30 \%$ weightage is for internal and $70 \%$ weightage is for external. For the course Computer Graphics the Net CO Attainment is $=1.77$.

Table 1. CO-PO Mapping

\begin{tabular}{|c|c|c|c|c|c|c|c|c|c|c|c|c|}
\hline & PO1 & PO2 & PO3 & PO4 & PO5 & PO6 & PO7 & PO8 & PO9 & PO10 & PO11 & PO12 \\
\hline CO1 & 3 & 3 & 1 & 1 & 1 & 1 & 1 & & 1 & & 1 & \\
\hline CO2 & 3 & 3 & 1 & 1 & 1 & & 1 & 1 & 1 & 2 & 1 & \\
\hline CO3 & 3 & 3 & 2 & 2 & 1 & 2 & 1 & & & & & \\
\hline CO4 & 3 & 3 & 1 & 2 & 2 & & 1 & 3 & 1 & & 3 & 1 \\
\hline CO5 & 1 & 1 & & & 1 & 3 & 1 & & 3 & 3 & 2 & 2 \\
\hline
\end{tabular}

\section{ASSESSMENT PROCESS}

The assessment process is based on utilizing direct and indirect tools for attaining PEOs and POs. The direct tool includes internal and external results, project evaluations and percentage of placements. The indirect tool utilizes conducting surveys by giving a set of questions to various stakeholders like alumni, employers and students.

\section{A. Subjects Assessment}

The subject assessment is based on student's performance in internal and external examinations. This also includes the performance of students in various assignments and quizzes. The Table 2 shows expected and actual attainment of a particular batch in Computer Graphics. The table also shows overall attainment of all subjects. 
Table 2. Internal \& External

\begin{tabular}{|c|c|c|c|c|c|c|c|c|c|c|c|c|}
\hline \multirow{3}{*}{ Course } & \multicolumn{12}{|c|}{ Internal \& External } \\
\hline & PO1 & PO2 & PO3 & PO4 & PO5 & PO6 & PO7 & PO8 & PO9 & PO10 & PO11 & PO12 \\
\hline & \multicolumn{12}{|c|}{ Expected PO Attainment } \\
\hline $\begin{array}{l}\text { Computer } \\
\text { Graphics }\end{array}$ & 2.6 & 2.6 & 1.25 & 1.5 & 1.2 & 2 & 1 & 2 & 1.5 & 2.5 & 1.75 & 1.5 \\
\hline \multirow[t]{2}{*}{ All Subjects } & 2.18 & 2.27 & 2.11 & 2.24 & 1.77 & 1.61 & 1.94 & 1.72 & 1.86 & 1.66 & 1.96 & 2.19 \\
\hline & \multicolumn{12}{|c|}{ Actual PO Attainment } \\
\hline $\begin{array}{l}\text { Computer } \\
\text { Graphics }\end{array}$ & 1.01 & 1.01 & 0.48 & 0.58 & 0.46 & 0.78 & 0.39 & 0.78 & 0.58 & 0.97 & 0.68 & 0.58 \\
\hline All Subjects & 1.44 & 1.47 & 1.34 & 1.47 & 1.15 & 1.02 & 1.27 & 1.08 & 1.20 & 1.03 & 1.29 & 1.41 \\
\hline
\end{tabular}

\section{B. Projects}

The project development also plays an important role in the attainment of program objectives. A internal project committee comprising project coordinator and supervisors evaluate the projects on regular basics. The university appointed external examiner also evaluates the projects at the end of the semester. The project attainments are shown in Table 3 and Table 5.

Table 3. Expected Direct Attainment

\begin{tabular}{|l|l|l|l|l|l|l|l|l|l|l|l|l|}
\hline Direct & PO1 & PO2 & PO3 & PO4 & PO5 & PO6 & PO7 & PO8 & PO9 & PO10 & PO11 & PO12 \\
\hline Result Of Courses & 2.18 & 2.27 & 2.11 & 2.24 & 1.77 & 1.61 & 1.94 & 1.72 & 1.86 & 1.66 & 1.96 & 2.19 \\
& & & & & & & & & & & & \\
\hline Project & 1.98 & 2.33 & 2.00 & 1.33 & 1.91 & 1.33 & 1.50 & 1.78 & 2.56 & 1.00 & 1.43 & 1.63 \\
\hline Placement & 2.00 & 1.00 & 3.00 & & 3.00 & 3.00 & & 2.00 & 3.00 & 3.00 & 3.00 & 1.00 \\
\hline PO Attainment & 2.08 & 1.97 & 2.31 & 1.45 & 2.11 & 1.89 & 1.34 & 1.80 & 2.32 & 1.83 & 2.09 & 1.75 \\
\hline
\end{tabular}

Table 4. Expected Indirect Attainment

\begin{tabular}{|l|l|l|l|l|l|l|l|l|l|l|l|l|}
\hline Indirect & PO1 & PO2 & PO3 & PO4 & PO5 & PO6 & PO7 & PO8 & PO9 & PO10 & PO11 & PO12 \\
\hline Exit Survey & 2.00 & 1.80 & 2.67 & 2.25 & 2.00 & 3.00 & 2.00 & 2.25 & 2.33 & 1.83 & 2.25 & 2.00 \\
\hline Alumni Survey & 3.00 & 2.50 & 2.00 & 1.67 & 2.50 & 3.00 & 3.00 & 2.25 & 2.50 & 3.00 & 2.60 & 2.00 \\
\hline $\begin{array}{l}\text { Curriculum } \\
\text { Feedback }\end{array}$ & & 2.50 & 1.33 & 3.00 & 3.00 & & 2.00 & 2.00 & 3.00 & 1.00 & 2.00 & \\
\hline $\begin{array}{l}\text { Employer } \\
\text { Feedback }\end{array}$ & 3.00 & 2.75 & 3.00 & 1.67 & 1.67 & 3.00 & 3.00 & 3.00 & 3.00 & 2.50 & 2.33 & 2.50 \\
\hline \begin{tabular}{l} 
PO Attainment \\
\hline
\end{tabular} & 2.00 & 2.39 & 2.25 & 2.15 & 2.29 & 2.25 & 2.50 & 2.38 & 2.71 & 2.08 & 2.30 & 1.63 \\
\hline
\end{tabular}

\section{Placements}

The assessment process also uses placement results in attainment of PEOs and POs. The placement evaluations are based on the percentage of placements, package and number of offers. The Net $\mathrm{CO}$ attainment formula for placement is straight forward and is defined as:

If $($ Per $>=75 \%)$ than

Attainment $=3$

Elseif $($ Per $>=60 \%)$ than

Attainment $=2$

Else

Attainment $=1$
In case if attainment is 3 then Actual Attainment is equal to Expected Attainment.

\section{Alumni Survey}

An online survey is conducted once a year to get feedback from Alumni. The feedback is assessed during attainment process. The survey helps in bridging the gap between industry and institute.

\section{E. Exit Survey}

The exit survey is conducted at the end of the post graduate course to take the feedback from the students. The survey is assessed during the attainment process. 


\section{F. Curriculum Feedback}

The curriculum feedback is conducted in the last semester of course to get feedback regarding the course contents and its applicability in real life and placements. The feedback is used in assessment process and would also help in designing the curriculum if the institute is autonomous. This would help the students to have better exposure in current market trends.

\section{G. Employer Feedback}

An employer feedback is taken from industry person where the students were placed. The different parameters were included in the form related to skills and ability of graduated student.

\section{PROGRAM OUTCOME CALCULATION}

The program outcomes are calculated by direct and indirect tools. The $50 \%$ contribution of direct tools and $50 \%$ contribution of indirect tools were taken in PO attainments.

In direct PO attainment the following weightage is given

$$
\begin{aligned}
\text { Direct }= & 0.50 * \text { Result }+0.25 * \text { Project } \\
& +0.25 * \text { Placement }
\end{aligned}
$$

In indirect PO attainment the following weightage is given to various surveys

$$
\begin{gathered}
\text { Indirect }=0.25 * \text { Exit }+0.25 * \text { Alumni }+ \\
0.25 * \text { Curriculum }+0.25 * \text { Employer }
\end{gathered}
$$

The direct and indirect attainments are given in Table 4, 5, 6 and 7 .

The final PO attainment is calculated as

$$
\text { Final PO Attainment }=\frac{\text { Actual_PO } * 100}{\text { Expected_PO }}
$$

Table 7 gives final PO attainment.

The PEO are calculated by taking average of mapped Program Outcomes(POs).

$$
\text { PEO = Average }(\text { Mapped POs })
$$

The mapping is shown in Table 8 .

The Figure 4 gives PEO attainments of last four batches of post graduate course. All PEO attainments are above $80 \%$. For any particular PG program one has to set the targets and if the targets are not achieved then gap analysis is to be performed. The same procedure is to be followed for PO attainments.

Table 5. Actual Direct Attainment

\begin{tabular}{|l|c|c|c|c|c|c|c|c|c|c|c|c|}
\hline Direct & PO1 & PO2 & PO3 & PO4 & PO5 & PO6 & PO7 & PO8 & PO9 & PO10 & PO11 & PO12 \\
\hline $\begin{array}{l}\text { Result of } \\
\text { Courses }\end{array}$ & 1.44 & 1.47 & 1.34 & 1.47 & 1.15 & 1.02 & 1.27 & 1.08 & 1.20 & 1.03 & 1.29 & 1.41 \\
\hline Project & 1.61 & 1.83 & 1.55 & 1.11 & 1.54 & 1.11 & 1.28 & 1.41 & 1.89 & 0.78 & 1.15 & 1.35 \\
\hline Placement & 2.00 & 1.00 & 3.00 & & 3.00 & 3.00 & & 2.00 & 3.00 & 3.00 & 3.00 & 1.00 \\
\hline PO Attainment & 1.62 & 1.44 & 1.81 & 1.01 & 1.71 & 1.54 & 0.96 & 1.39 & 1.82 & 1.46 & 1.68 & 1.30 \\
\hline
\end{tabular}

Table 6. Actual Indirect Attainment

\begin{tabular}{|l|l|l|l|l|l|l|l|l|l|l|l|l|}
\hline Indirect & PO1 & PO2 & PO3 & PO4 & PO5 & PO6 & PO7 & PO8 & PO9 & PO10 & PO11 & PO12 \\
\hline Exit Survey & 1.54 & 1.39 & 2.05 & 1.73 & 1.54 & 2.31 & 1.54 & 1.73 & 1.80 & 1.41 & 1.73 & 1.54 \\
\hline Alumni Survey & 2.60 & 2.17 & 1.73 & 1.44 & 2.17 & 2.60 & 2.60 & 1.95 & 2.17 & 2.60 & 2.25 & 1.73 \\
\hline $\begin{array}{l}\text { Curriculum } \\
\text { Feedback }\end{array}$ & & 1.63 & 0.87 & 1.96 & 1.96 & & 1.31 & 1.31 & 1.96 & 0.65 & 1.31 & \\
\hline $\begin{array}{l}\text { Employer } \\
\text { Feedback }\end{array}$ & 2.80 & 2.57 & 2.80 & 1.56 & 1.56 & 2.80 & 2.80 & 2.80 & 2.80 & 2.33 & 2.18 & 2.33 \\
\hline PO Attainment & 1.74 & 1.94 & 1.86 & 1.67 & 1.81 & 1.93 & 2.06 & 1.95 & 2.18 & 1.75 & 1.87 & 1.40 \\
\hline
\end{tabular}

Table 7. Final PO Attainment

\begin{tabular}{|l|l|l|l|l|l|l|l|l|l|l|l|l|}
\hline & PO1 & PO2 & PO3 & PO4 & PO5 & PO6 & PO7 & PO8 & PO9 & PO10 & PO11 & PO12 \\
\hline Expected PO & 2.04 & 2.18 & 2.28 & 1.80 & 2.20 & 2.07 & 1.92 & 2.09 & 2.51 & 1.96 & 2.19 & 1.69 \\
\hline Actual PO & 1.68 & 1.69 & 1.84 & 1.34 & 1.76 & 1.73 & 1.51 & 1.67 & 2.00 & 1.61 & 1.78 & 1.35 \\
\hline Attainment (\%) & 82.19 & 77.59 & 80.63 & 74.66 & 79.76 & 83.80 & 78.53 & 79.90 & 79.65 & 82.08 & 81.01 & 79.81 \\
\hline
\end{tabular}


Table 8. PEO Attainment

\begin{tabular}{|c|c|c|c|c|}
\hline PEOs & Mapped POs & PEO Expected & PEO Attained & Attainment (\%) \\
\hline PEO1 & PO1, PO2, PO3, PO5 & 2.18 & 1.74 & 80.02 \\
\hline PEO2 & PO1, PO2, PO5, PO6, PO7, PO9, PO10, PO11 & 2.13 & 1.72 & 80.54 \\
\hline PEO3 & PO3, PO4, PO6, PO10 & 2.03 & 1.63 & 80.46 \\
\hline PEO4 & PO5, PO8, PO9, PO11 & 2.25 & 1.80 & 80.07 \\
\hline PEO5 & PO3, PO10, PO11, PO12 & 2.03 & 1.64 & 80.91 \\
\hline
\end{tabular}

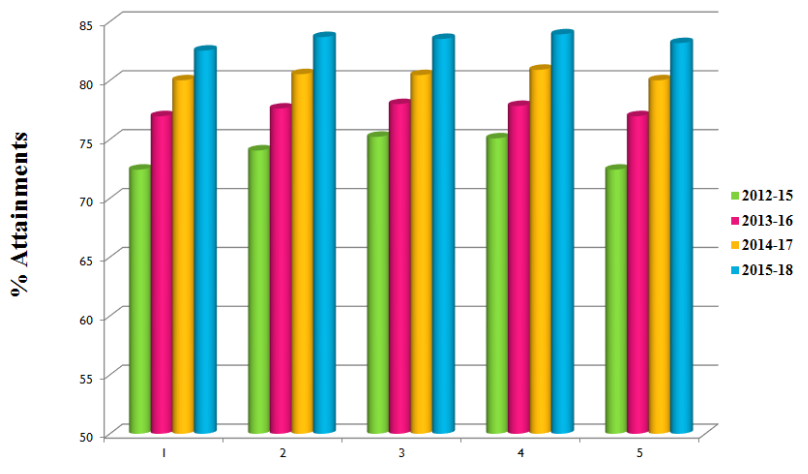

Programme Educational Objectives

Fig.4. Previous Four Batches Attainments.

\section{CONCLUSION}

Today, most of the engineering educational institutions are assessing their degree programs on the basis of outcome based education for improving their curriculum design, teaching methodologies, assessment and evaluation process. There are clear guidelines prescribed by accreditation bodies of Indian Government for each institute for defining, assessing various Program Outcomes in correlation NBA graduate attributes.

In this paper we discussed about the process of attaining Program Outcome and Program Educational Objectives for post graduate program. This work will help in assessing the teaching learning process of the institute and thus would help in calculating the attainments of different batches of a particular post graduate program.

\section{REFERENCES}

[1] Washington Accord, [online] Available: www.ieagreements.org/accords/washington

[2] National Board of Accreditation [online] Available: www.nbaind.org

[3] Ramchandra, S., Maitra, S, Mallikarjuna Babu.K, "Method for estimation of attainment of program outcome through course outcome for outcome based education", 2014 IEEE International Conference on MOOC, Innovation and Technology in Education (MITE), pp. 7 12, 2014.

[4] M. S. Jaafar, N. K. Nordin, R. Wagiran, A. Aziz, M. J. M. M. Noor, M. R. Osman, J. Noorzaei and F. N. A. Abdulaziz, "Assessment Strategy for an Outcome Based
Education", International Conference on Engineering Education, July 2008.

[5] Shallu Bassi, V. K. Chandna, Sangeeta Singh, "Analysis of course outcomes of HVE-a tool for assessment of programme outcomes", MOOCs Innovation and Technology in Education (MITE), 2015 IEEE 3rd International Conference on, pp. 35-37, 2015.

[6] Parveen P Terang, Sanjiba Kr. Bisoyi, Vinay Kumar Chandna, "Weightage factor analysis between programme Outcomes and course Outcomes: A case study", MOOCs Innovation and Technology in Education (MITE) 2015 IEEE 3rd International Conference on, pp. 84-87, 2015.

[7] Vinay Kumar Chandna, "Course outcome assessment and improvement on weak student", MOOCs Innovation and Technology in Education (MITE) 2015 IEEE 3rd International Conference on, pp. 38-40, 2015.

[8] Amit Kumar Roy, Gunjan Varshney, V. K. Chandna, "Learning through modern tools in power quality to evaluate course outcome", MOOCS Innovation and Technology in Education (MITE) 2015 IEEE 3rd International Conference on, pp. 96-99, 2015.

[9] Akash Rajak, Ajay Shrivastava, D.P. Shrivastava, "Automating Outcome Based Education for the Attainment of Course and Program Outcomes",The Fifth HCT Information Technology Trends (ITT 2018), Dubai, UAE, pp. 373-376, 2018.

[10] Gary KW Wong, H. Y. Cheung, "Outcome-based teaching and learning in computer science education at sub-degree level", International Journal of Information and Education Technology, vol. 1, no. 1, pp. 40, 2011.

[11] K.Y. Tshai, J.-H. Ho, E.H. Yap, H.K. Ng, "Outcomebased Education -The Assessment of Programme Educational Objectives for an Engineering Undergraduate Degree", Engineering Education, vol. 9, no. 1, 2014.

[12] Srividya Bansal, Ajay Bansal, Odesma Dalrymple, "Outcomebased Education Model for Computer Science Education", Journal of Engineering Education Transformations, vol. 28, no. 2 \& 3, pp. 113-121, 2015.

\section{Authors' Profiles}

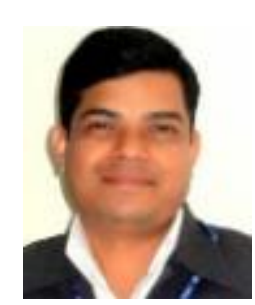

Akash Rajak is working as Associate Professor in KIET Group of Institutions, Ghaziabad, India. He is having 16 years of teaching and research experience. He completed Ph.D in computer science from Barkatullah University, Bhopal in the field of temporal data mining. He did M.C.A from U.T.D Campus, Dr. H. S. Gour University, Sagar (M.P) in 2002. He is a life member of various professional societies like ACEEE, IACSIT, IAENG etc. He is a reviewer of various international 
conferences, journals and books. His research interest includes $\mathrm{AI}$ and Data mining.

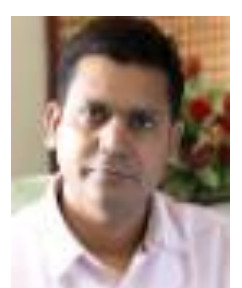

Ajay K Shrivastava is working as Professor in KIET Group of Institutions, Ghaziabad, India. He is having 16 years of teaching and research experience. He completed Ph.D in computer science from Dr. H. S. Gour University, Sagar in the field of Embedded Systems. He did M.C.A from U.T.D Campus, Dr. H. S. Gour University, Sagar (M.P) in 2002. He is a member of various professional societies like IEEE, ACEEE, IACSIT etc. He is a member of the editorial boards of International Journals and Reviewer of the various journals and conferences organized by ACEEE.

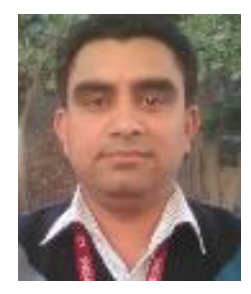

Shashank Bhardwaj is working as Assistant Professor in Department of Computer Applications in KIET Group of institutions since 2006. He has done his Doctorate in the field of e-health monitoring. His research interest includes Database Designing and Artificial Intelligence.

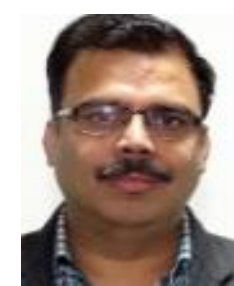

Arun Kumar Tripathi received B.Sc. (Electronics) degree from Dr. Hari Gour University Sagar and M. Tech. from Uttar Pradesh Technical University in Computer Science and Engineering. He has completed Ph.D. from National Institute of Technology, Kurukshetra. He joined the KIET group of Institution, Ghaziabad in 2003 and presently working as Associate Professor. His area of interest is Mobile and Wireless Communication. He has published more than 35 papers in various International, National conferences and Journals.

How to cite this paper: Akash Rajak, Ajay Kumar Shrivastava, Shashank Bhardwaj, Arun Kumar Tripathi, "Assessment and Attainment of Program Educational Objectives for Post Graduate Courses", International Journal of Modern Education and Computer Science(IJMECS), Vol.11, No.2, pp. 26-32, 2019.DOI: 10.5815/ijmecs.2019.02.04 